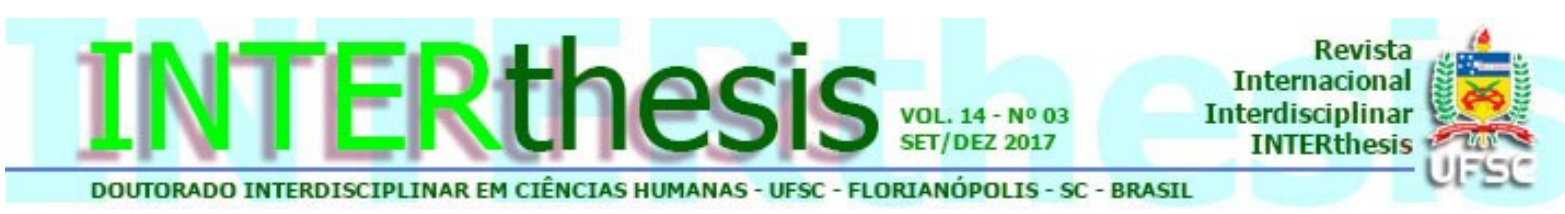

\title{
IDENTIDADE, PERTENCIMENTO E ENGAJAMENTO POLÍTICO NAS MídIAS SOCIAIS
}

Resumo:

Anny Rochelly Vieira Santos ${ }^{2}$

Adotando uma perspectiva interdisciplinar, este artigo analisa as mudanças introduzidas pelas mídias sociais na sociedade partindo de conceitos como identidade, território e políticas públicas e sua transposição para o mundo virtual, aqui considerado objeto multidisciplinar. As mídias sociais como território de pertencimento, onde é possível a governos estabelecerem mecanismos de controle de políticas públicas mais democráticas e participativas devido à interação virtual, são premissas defendidas neste artigo, que ao final mostra como governo e comunidade hoje têm a possibilidade de dialogar e construir ações, projetos e programas a partir do engajamento e do ativismo político praticado nas redes sociais. Como metodologia, foi realizada uma revisão bibliográfica que permitiu a discussão de conceitos oriundos de distintas áreas de conhecimento, estabelecendo uma relação entre identidade, território e mídias sociais.

Palavras-chave: Identidade. Território. Mídias Sociais. Multidisciplinaridade.

\section{INTRODUÇÃO}

Desde a sua popularização, as mídias sociais realizam uma verdadeira revolução na forma de elaborar e acessar conteúdo, seja ele jornalístico, de lazer ou informacional. Em um só ambiente, as pessoas leem notícias, acompanham os amigos por fotos e vídeos e compartilham links de forma gratuita e ilimitada. $\mathrm{O}$ tempo e a diluição do espaço são elementos-chave nesse processo, pois é a partir deles e por causa deles que todo conteúdo é produzido e distribuído mais rapidamente, como se pudéssemos acompanhar cada link em tempo real. Esse mesmo tempo modifica, de forma acelerada, valores e conceitos que antes alteravam-se lentamente, fazendo com que a modernidade seja cada vez mais líquida (BAUMAN, 1999 e 2000) e produza a chamada crise de identidade e o fenômeno da solidão de massa. Estamos cercados de pessoas no ambiente virtual, mas as nossas diferenças não são bem aceitas nesse meio que tende a padronizar

1 Doutor em Ciências Sociais pela Universidade do Estado do Rio de Janeiro. Antropólogo e documentarista. Pesquisador do Instituto de Tecnologia e Pesquisa. Professor do Programa de Pósgraduação Sociedade, Tecnologias e Politicas Públicas, Maceió, AL, Brasil E-mail: pedrosimonard@gmail.com

${ }^{2}$ Mestranda no Programa de Pós-graduação Sociedade, Tecnologias e Políticas Públicas. Assessora de Comunicação do Instituto Federal de Alagoas, Maceió, AL, Brasil E-mail: nanyrochelly@gmail.com 
emoções, modo de vestir, de falar e de reagir aos fatos, quando as interações se dão dentro de comunidades virtuais, ao mesmo tempo em que permite ao interagente contato com múltiplas culturas e redes variadas que diluem padrões de comportamento. A identidade, que por si só já apresenta natureza negociável e revogável, torna-se ainda mais instável neste ambiente, apresentando-se fluida e frágil, assumindo múltiplas facetas em prol da exibição nas redes.

O sentimento de pertencimento une os sujeitos em torno de objetivos comuns, confortáveis em determinado local e, nesse sentido, a Internet, prioritariamente as mídias sociais, pode ser considerada espaço para que nela os indivíduos naveguem e produzam sentido, seja simbólico, social ou afetivo.

A Internet não é apenas espaço, livre de sentimentos e com sentido restrito ao geográfico, mas ambiente onde coexistem vários territórios, no qual, como em todo território, sentimentos de pertencimento e poderes invisíveis atuam em direção ao simbólico. Identidade e território, quando transpostos para as mídias sociais, intensificam-se em sua essência, permitindo o surgimento do ativismo nas redes com a formação de grupos de atuação política específicos, ativismo que se mostra ativo e intenso devido à possibilidade de o interagente ${ }^{3}$ manter sua identidade no anonimato. Interagentes com objetivos semelhantes ganham força nas redes. Governos, buscando comunicar-se com esses grupos e também para atender às Leis da Informação e Transparência, que exigem publicidade dos seus atos, aderem às mídias sociais e, consequentemente, propiciam uma maior participação, controle (orçamentário, de políticas públicas e ações governamentais) e engajamento político dos cidadãos (CASTELLS, 2013; LEMOS e LEVY, 2010), muito embora grupos marginalizados socialmente possam permanecer excluídos no mundo virtual (RUEDIGER, 2002) e não participem de movimentos ou atividades que possam ser compreendidas como maior participação democrática. É importante salientar que muitas das contribuições postadas nas páginas e portais oficiais dos diferentes níveis de governo hospedadas nas mídias sociais são vazias de conteúdo ou qualidade. Contudo, estas postagens permitem que indivíduos tornem-se

\footnotetext{
3 O termo "interagente", proposto por Primo (2003), substitui "receptor" e "usuário" porque estes últimos estariam indicando um papel subordinado do sujeito em todo o processo. Já o termo "interagente" remete à participação e construção de conteúdo. Em alinhamento ao que está sendo discutido nesse artigo e considerando as premissas defendidas aqui, utilizaremos o termo "interagente" em todo o texto sempre que nos referirmos àquele que interage por intermédio do computador.
}

R. Inter. Interdisc. INTERthesis, Florianópolis, v.14, n.3, p.16-31 Set.-Dez. 2017 
mensuráveis para a esfera pública no momento em que curtem, comentam ou compartilham conteúdos governamentais em suas páginas. A partir destas interações, as mídias sociais produzem dados, gráficos e informações sobre os interagentes que são repassados aos governos que podem, desta maneira, quantificar e analisar os cidadãos que interagem com os conteúdos governamentais disponíveis online, bem como tomar ciência de quais conteúdos mais despertam a iniciativa e o interesse dos interagentes.

Este artigo pretende dirigir suas reflexões sobre como os interagentes podem contribuir para a construção de políticas públicas menos burocráticas e inflexíveis, em direção a uma comunicação horizontal e colaborativa. Para isso, discutiremos conceitos como identidade, levando em consideração sua aplicabilidade nas mídias sociais e como se torna mais fluida e adaptável ao ambiente digital. Em seguida, abordaremos o conceito de território, considerando que a Internet ultrapassa o terreno do espaço e gera sentimento de pertença quando carrega em si elementos sociais e afetivos dos seus membros. Finalizando, traremos reflexões sobre as políticas públicas e como estão sendo transformadas com o advento do digital e com a participação popular dos indivíduos nas mídias sociais, inclusive discutindo brevemente o engajamento político e o ativismo nas redes. A metodologia utilizada é baseada no entrelaçamento dos conceitos identidade, território e mídia social a partir da reflexão teórica de autores como Bauman, Lemos, Hall, Castells, Haesbaert, Moreira, Marzulo, Primo, Recuero, entre outros estudiosos dos temas tratados neste artigo.

\section{IDENTIDADE E MÍDIAS SOCIAIS}

Identidade não é um conceito que se refira a algo estável, finalizado e imutável. A identidade é fluida, provisória, política e absolutamente negociável, ou seja, adaptável à maneira como se dá a interação social e política (BAUMAN, 2005; HALL 2006 e 2014; CARDOSO DE OLIVIERA, 2000). Na "modernidade tardia" (HALL, 2006) as velhas identidades unificadoras e estabilizadoras, sobretudo a identidade nacional, é substituída por uma identidade híbrida descentrada, composta por várias posições de identidade. "As velhas identidades que por tanto tempo estabilizaram o mundo moderno, estão em declínio, fazendo surgir novas 
identidades e fragmentando o indivíduo moderno, até aqui visto como um sujeito unificado" (CANCLINI, 2003, p.7).

A globalização teve como consequência dialética o surgimento de fundamentalismos, entre os "vagabundos", e o surgimento de uma identidade fluida, compartilhada pelos "turistas", que têm como um de seus principais modos de se expressar a Internet e as mídias sociais (BAUMAN, 2005). Discorrendo sobre as comunidades virtuais, Bauman afirma que elas tornam mais difícil o ato de substanciar a identidade pessoal, por isso tentamos criar ou encontrar novos grupos para que vivenciemos o pertencimento e a identidade se manifeste em seu aspecto relacional, ou seja, a forma que o outro nos enxerga também constrói nossa identidade.

Em sua concepção crítica, Bauman declara que a identidade é "como um manto leve, pronto a ser despido a qualquer momento" (BAUMAN, 2005, p. 37). Contudo, na sociedade pós-moderna ainda nos deparamos com identidades sólidas e duráveis no que tange às identidades de movimentos fundamentalistas, essencialistas e de alguns grupos étnicos. De acordo com Bauman (1999, 2000 e 2005) e, sobretudo, Hall (2006), estas identidades mais essencialistas são também uma consequência do processo de globalização e formam par dialético com a identidade fluida.

A sociedade ocidental contemporânea se caracteriza pela rapidez, pelo mutável, pelo volúvel, o que se reflete nas identidades que surgem das interações sociais que nela ocorrem e se formam. As identidades fixas são superadas porque "flutuar na onda das oportunidades mutáveis e de curta duração parecem mais atraentes" (BAUMAN, 2005, p. 60). Para Woodward (2000), as mudanças nos padrões de produção e consumo geram estas novas identidades globalizadas e plurais. "É o colapso das velhas certezas e a produção de novas formas de posicionamento" (WOODWARD, 2000, p. 25). Segundo esta autora, há hoje uma multiplicidade de centros, isto é, muitos e diversos lugares a partir dos quais novas identidades podem surgir e novos sujeitos podem se expressar. Neste sentido, há uma valorização das identidades múltiplas, seja entre os grupos sociais à margem da sociedade, seja entre aqueles grupos sociais que são hegemônicos. A diferença tem papel fundamental nesse processo de construção de identidades. A fluidez e a multiplicidade são a essência do ambiente virtual, local onde a multiplicidade de 
vozes se manifesta e se reúne, muitas vezes, em uma forma de manifesto contra a opressão da vida real. Woodward identifica a diferença como algo positivo porque, ao invés de ser associada à marginalização ou exclusão, está relacionada à diversidade, à heterogeneidade e ao hibridismo. Desta maneira, a fluidez e a multiplicidade do ambiente virtual induzem e propiciam a formação e o surgimento de variadas comunidades virtuais que permitem o surgimento de identidades múltiplas e fluidas, tal qual as comunidades nas quais elas se manifestam.

Hall (2005) defende que na modernidade tardia ou pós-modernidade (HARVEY, 2014) há uma crise de identidade devido a um duplo deslocamento: a descentração dos indivíduos tanto do seu lugar no mundo social e cultural quanto de si mesmos. Analisando o processo por meio do qual a identidade una se transforma na identidade descentrada, ele identifica as três fases deste processo: no lluminismo, havia uma identidade centrada, unificada e imutável:

A pessoa é um indivíduo totalmente centrado, unificado, dotado das capacidades de razão, de consciência e de ação, cujo centro consistia em um núcleo interior, que emergia pela primeira vez quando o sujeito nascia e com ele se desenvolvia, mesmo que permanecesse essencialmente o mesmo ao longo da existência do indivíduo; o centro essencial do eu era a identidade da pessoa (HALL, 2005, p.10).

A segunda fase surge com a conformação do sujeito sociológico, onde a identidade se forma na intercessão com o outro, uma concepção interativa da construção identitária fruto da interação do sujeito "com outras pessoas importantes para ele" (HALL, 2005, p.11). O sujeito já não goza de muita autonomia frente à sociedade, como o sujeito lluminista, mas depende do grupo, depende da sociedade para desenvolver, operar e alterar sua identidade. Por último, surge o sujeito pósmoderno que não possui mais uma identidade fixa ou permanente, quando o sujeito ocupa posições identitárias variadas na sua vida cotidiana que são acionadas de acordo com suas interações sociais diárias. A identidade é descentrada, gerando um sujeito híbrido no qual existem vários centros identitários. A identidade é uma “'celebração móvel', formada e transformada continuamente em relação às formas pelas quais somos representados ou interpelados nos sistemas culturais que nos rodeiam" (HALL, 2005, p. 13).

Hall sugere que, ao invés de utilizarmos o termo "identidade", foquemos na palavra "identificação", já que estamos nos referindo a um processo contínuo, em constante mutação. "A identidade surge da falta de uma inteireza que é preenchida a partir de nosso exterior, pelas formas através das quais nós imaginamos ser vistos R. Inter. Interdisc. INTERthesis, Florianópolis, v.14, n.3, p.16-31 Set.-Dez. 2017 
pelos outros" (HALL, op.cit., p. 39). Em contrapartida a este descentramento e como consequência do mesmo processo a partir do qual este ocorre, surgem identidades locais, fortalecidas com a globalização, tornando-se desvinculadas ou desalojadas, que resistem à marginalização e, ao mesmo tempo, as relações de produção globalizadas insistem em lançar os sujeitos locais ou "vagabundos", no dizer de Bauman. Ele acredita que as identidades se tornam mais posicionais, políticas, plurais e diversas a partir do fenômeno da globalização.

A identidade tem um caráter faltoso ou incompleto (HALL, 2006). Ela se apresenta como "pontos de apego temporário às posições-de-sujeito que as práticas discursivas constroem para nós" (HALL, 2006, p. 111). Na sua concepção, identidades podem ser assim definidas:

As posições que o sujeito é obrigado a assumir, embora "sabendo" [...] sempre, que elas são representações, que a representação é sempre construída ao longo de uma "falta", ao longo de uma divisão, a partir do lugar do Outro e que, assim, elas não podem, nunca, ser ajustadas idênticas - aos processos de sujeito que são nelas investidos (HALL, 2006, p. 111).

Enquanto consequência das relações sociais, a identidade está sujeita a relações de poder, conforme nos mostra Silva (2014). O poder se manifesta, por exemplo, quando se constrói uma identidade normativa e todas as outras que surgem são consideradas invisíveis frente à normativa e considerada invisível por esta última. $O$ ambiente virtual pode minimizar esta diferenciação na medida em que oportuniza a expressão dos invisíveis, mas pode também intensificar a opressão, a discriminação e a violência contra os marginalizados quando o anonimato pode dar livre vazão a propostas racistas, sexistas, homofóbicas etc.

Castells (2001), por sua vez, divide a identidade em três tipos: legitimadora (dominação), de resistência (marginalizados) e de projeto (transformação social). A identidade de resistência, para o autor, é a que leva à formação de comunidades e, por este motivo, é considerada a mais importante na nossa sociedade em rede. A identidade de projeto, por sua vez, é originada a partir da segunda e produz sujeitos críticos e atuantes, que redefinem sua posição na sociedade. "Os anseios de expressar a própria identidade e de tê-la reconhecida de forma concreta pelos outros são cada vez mais contagiantes" (CASTELLS, apud HOOLSON, 2001, p. 45). Castells acrescenta que as pessoas resistem ao processo de individualização, tendendo a agrupar-se em organizações comunitárias que geram um sentimento de pertença e também identidade cultural. Seguindo esta linha de raciocínio, a R. Inter. Interdisc. INTERthesis, Florianópolis, v.14, n.3, p.16-31 Set.-Dez. 2017 
identidade legitimadora, para Castells, está em crise e a identidade de resistência ganha força neste cenário. "É possível que dessas comunas, novos sujeitos - isto é, agentes coletivos de transformação social - possam surgir, construindo novos significados em torno da identidade de projeto" (CASTELLS, op.cit, p. 86). As identidades de projeto, nesta perspectiva, crescem exponencialmente na Internet, ambiente no qual as comunas são mais facilmente formadas e fomentadas.

Nas mídias sociais, a construção e a manutenção da identidade tornam-se ainda mais fluidas e sujeitas à aprovação a partir da exibição dessas identidades nas redes. A volatilidade do espaço virtual propicia que esta característica seja intensificada, assim como a multiplicidade identitária manifestada na vida real e apropriada pelos indivíduos nas mídias sociais. Identidades políticas, plurais e diversas compõem o cenário digital da atualidade. Neste sentido, surgem cada vez mais comunidades virtuais nas mídias sociais onde identidades de resistência se formam, muitas delas sem uma diretriz política mais forte. Contudo, muitas destas novas comunidades conseguem desenvolver identidades de projeto, criando um território próprio onde valores e signos comuns surgem e aglutinam os membros destas comunidades em torno de objetivos comuns. Estas comunidades virtuais transformam o sentido de espaço e território nas mídias sociais, conforme veremos a seguir.

\section{ESPAÇO/TERRITÓRIO E MÍDIAS SOCIAIS}

A noção de território enfatiza a ocupação de um espaço geográfico particular no qual a comunidade constrói sua autonomia cultural, social e sua autoestima. Um território constitui componente singular de identidade devido à ideia de que um grupo social, confrontado com uma situação histórica peculiar, realça determinados traços culturais que julga relevantes em tal ocasião. Marzulo (2007) estabelece relação entre espaço e identidade social, defendendo que o espaço carrega um sentido essencialmente geográfico e passa a ser território quando é associado ao sentimento de pertencimento e ao enraizamento socioeconômico, ou seja, quando nele está imbuído um sentido simbólico e referencial. Santos (2007) é pontual em sua definição:

O território deve superar o dualismo social-espacial. Ele é o lugar em que desembocam ações, paixões, poderes, forças, fraquezas, isto é, onde a história do homem plenamente se realiza a partir das manifestações da sua 
existência [...] O território [...] mostra que há coisas que não se podem desmanchar (SANTOS, 2007, p. 11).

A partir da definição de Santos, pode-se deduzir que o território carrega em si elementos subjetivos. "O território não é apenas o conjunto dos sistemas naturais e de sistemas de coisas superpostas. O território tem que ser entendido como o território usado, não o território em si. O território usado é o chão mais a identidade" (SANTOS, 2007, p. 13).

Concordando com Santos, Haesbaert (2007) sustenta que o território, enquanto valor, simboliza a necessidade humana de estabelecer relação forte com o seu espaço de vida. O poder do laço territorial é abordado pelo autor, conceito que inclui valores éticos, espirituais, simbólicos e afetivos. "Ele [o território] é parcela da identidade, fonte de relação de essência afetiva ou mesmo amorosa" (HAESBAERT, 2007 , p. 71). Haesbaert afirma que o território é definido com base nas relações sociais ou culturais no qual está imerso, relações essas que também se configuram como relações de poder. Ele é cuidadoso, no entanto, ao não menosprezar a base material inerente ao território, considerando que o território é relacional, assim como a identidade: ele incorpora conjunto de relações sociais, envolve processos sociais e espaço material e não significa apenas enraizamento ou estabilidade, mas também movimento e fluidez.

Podemos relacionar, facilmente, as definições de identidade e território, observando uma estreita relação entre os conceitos na medida em que ambos estão ancorados na relação com o outro. Além do mais, os dois foram profundamente alterados com o surgimento da sociedade em rede. Haesbaert considera, inclusive, que a rede é o componente mais importante da territorialidade contemporânea. Neste sentido, ele desmonta a ideia de que haja uma desterritorialização na modernidade que faça desaparecer os territórios, alegando que este conceito está fortemente relacionado à dominação capitalista ao considerar que os grupos socialmente não-hegemônicos assumem uma situação passiva frente à dominação. Por isto, em lugar do conceito "desterritorialização" ele utiliza o conceito "reterritorialização" na medida em que o dominado, o não-hegemônico, ressignifica seu território de maneira a confrontar os grupos socialmente hegemônicos. Haesbaert defende uma des-re-territorialização. "O próprio território se torna mais complexo, múltiplo, [...] híbrido e flexível e, ao mesmo tempo, mais inflexível e 
fechado, marcado pelos muros que separam ricos e pobres" (HAESBAERT, 2007, p. 66).

Segundo Moreira (2007), o indivíduo marginalizado utiliza-se do contraespaço para tecer estratégias de resistência na sociedade pós-moderna. Lógica declarada de confrontamentos, marcado por conflitos de territorialidade, o contraespaço é "o modo espacial onde excluídos e dominados põem em questão a ordem espacial instituída, rejeitando ou copiando o modo de vida que a sociedade impõe. (...) [O contra-espaço] é uma luta por formas novas e democráticas do espaço" (MOREIRA, 2007, p. 103). Neste sentido, o novo espaço muitas vezes é resultado do movimento de contra-espaço que existia no velho espaço. A reestruturação de espaços, assim, acontece por conta da ação do contra-espaço e os conflitos presentes neste último remodelam constantemente o espaço. Num movimento dialético, o que era contra-espaço torna-se espaço quando se torna hegemônico.

O modo como a Internet e o ambiente digital vêm sendo ocupados e apropriados por comunidades formadas também por interagentes marginalizados é exemplo de contra-espaço. Quando são criados novos espaços de discussão e debate político, os quais incitam à participação e ao engajamento, há um contraespaço sendo investido por pessoas que questionam a realidade a sua volta. Ainda que de forma majoritária a Internet seja gerida pelos grupos sociais hegemônicos, o fato é que as opiniões e posicionamentos de pessoas que fora daquele ambiente não seriam expostas permitem a construção de uma política um pouco mais democrática e plural, embora sob as regras dos grupos socialmente hegemônicos. Estas regras e as limitações que elas impõem ao debate político no ciberespaço conduzem Bauman a construir uma visão pessimista sobre este tipo de debate no ambiente digital porque este propicia a segurança do isolamento e, concomitantemente, há um progressivo desaparecimento do espaço público aliado à desintegração da comunidade urbana e também à segregação. "Um território despojado de espaço público dá pouca chance para que as normas sejam debatidas, valores confrontados e negociados. Não há espaço para opinião local” (BAUMAN, 2000, p. 32). Talvez por isto, seja muito comum o confronto nas mídias onde pessoas, não raramente, em lugar de debaterem, ofendem-se umas às outras.

As comunidades existentes nas mídias sociais conformam-se como territórios. Nelas "desembocam ações, paixões, poderes, forças, fraquezas" (SANTOS, 2007, p. 
11), também estão presentes valores subjetivos e laços simbólicos estabelecidos entre seus membros. Percebe-se a existência de um sentimento de pertencimento à comunidade virtual quando se adere ao ambiente digital, o qual incorpora relações sociais em um movimento de fluidez e construção identitária que favorece a participação social.

\section{MÍDIAS SOCIAIS E CONTROLE DA COLETIVIDADE SOBRE OS GOVERNOS}

Com a expansão da internet e sua intensa utilização, as mídias sociais, mais comumente conhecidas como redes sociais, surgem como um próximo passo no avançar do homem pelo cenário digital. Recuero (2010) considera que as redes sociais são a comunicação que já era praticada na sociedade, antes mesmo de existir internet, ou seja, a comunicação tradicional e que estimula a sociabilidade entre as pessoas. Por isso, redes sociais, para esta autora, não representam exatamente o conceito de mídias sociais, que é o espaço virtual onde acontece a interação social. Recuero defende o uso do termo mídias sociais no sentido de simbolizar o conjunto de dinâmicas da rede social, ao passo que redes sociais são uma metáfora para os grupos sociais. Dessa forma, mídias sociais são assim conceituadas pela autora:

São as dinâmicas de criação de conteúdo, difusão de informação e trocas
dentro dos grupos sociais estabelecidos nas plataformas online (como sites
de rede social) que caracteriza aquilo que chamamos hoje de mídia social.
São as ações que emergem dentro das redes sociais, pela interação entre
as pessoas, com base no capital social construído e percebido que vão
iniciar movimentos de difusão de informações, construção e
compartilhamento de conteúdo, mobilização e ação social (RECUERO,
2010).

As mídias sociais possuem cinco características: conversação, menor concentração de poder no processo de comunicação, maior circulação de informações, novas formas de construção de sentido e maior capacidade de mobilização (RECUERO, 2010). Desta forma, adotarei o termo mídias sociais neste artigo, em concordância ao que está posto pela autora, ou ainda a nomenclatura sites de redes sociais=

As mídias sociais só existem porque seus membros interagem, compartilham e disseminam conteúdo de forma a alimentar o próprio sistema e aumentar o seu nível de influência perante os seguidores. Recuero (2011) afirma que elas possuem mecanismos de individualização, mostram as redes sociais de cada ator de forma pública e possibilitam que os mesmos construam interações nesses sistemas. Um R. Inter. Interdisc. INTERthesis, Florianópolis, v.14, n.3, p.16-31 Set.-Dez. 2017 
importante diferencial posto por esta autora é que os sites de redes sociais não são, por si só, redes sociais. "Eles podem apresentá-las, auxiliar a percebê-las, mas é importante salientar que são, em si, apenas sistemas. São os atores sociais que utilizam essas redes que constituem essas redes" (RECUERO, 2011, p. 103).

Lemos (2013) defende que as mídias sociais, assim como outros objetos e ferramentas nas mãos dos seres humanos, podem ser meros intermediários, atuando como pontes ou ligações entre sujeitos de forma a produzir resultados, ou mesmo actantes, produzindo ações e diferenças significativas. O autor acredita que qualquer luta política, levante ou ação social só acontece pelas relações entre humanos e não-humanos porque não é possível haver qualquer movimento social sem actantes humanos (LEMOS, 2013). Para ele, as revoluções que aconteceram no Egito e Tunísia em 2008, por exemplo, comprovam o poder dos celulares, mídias e mídias sociais, os quais "agiram como mediadores e tradutores de outros agentes (humanos e não-humanos) e fizeram sim sua parte para que as revoluções acontecessem" (LEMOS, 2013, p. 170).

É nesta direção que este artigo pretende dirigir suas reflexões, isto é, levando em consideração a importância das novas ferramentas tecnológicas na atualidade. As mídias sociais permitiram que a coletividade desenvolvesse novas estratégias de controle, pressão e comunicação com os diferentes níveis de governo, criando um novo espaço público de debate. Angelis (2015) relata os desafios de um novo serviço público e a necessidade de um governo que transforme o conhecimento coletivo em inteligência.

Governar com a sociedade, em vez de governar a sociedade, faz com que o próprio beneficiário possa contribuir no desenvolvimento da estratégia, do planejamento e da gestão dos diversos programas e projetos, melhorando a qualidade do gasto e da ação pública. A participação do cidadão e o estabelecimento de parcerias ajudam, e muito, na transformação da cultura da desconfiança e do curto prazo em uma cultura de colaboração e de longo prazo (ANGELIS, 2015, p. 17).

Para o autor, ainda há uma grande dificuldade do Estado, em pleno século $X X I$, de transformar a colaboração dos interagentes em conhecimento relevante e, mais adiante, em projetos e ações concretas. Ele lista as revoluções que estão transformando o setor público: tecnológica (web 2.0), demográfica (geração net), social (rede social) e organizacional (colaboração em massa). Angelis acredita que apenas a presença nas mídias sociais, por si só, não gera grandes mudanças 
devido ao excesso de informação e à dificuldade dos governos em tomar decisões a partir dos conteúdos coletados.

O conhecimento da multidão só produz mais incerteza e complexidade se não organizado por meio das práticas de Gestão do Conhecimento e sintetizado pela análise dos [...] sistemas inteligentes e Inteligência Organizacional (ANGELIS, 2015, p. 24).

Em sua concepção, apesar dos novos espaços de participação na sociedade civil, ainda há um alto grau de centralização do poder no Executivo e isolamento dos gestores públicos. Entretanto, ele reconhece que o processo colaborativo gera desenvolvimento humano, benefício social e efetividade das ações.

\begin{abstract}
Estamos em uma época em que o poder e a autoridade do governo e a legitimidade das políticas públicas vão se tornar ainda mais dependentes da democracia interativa. Portanto, o valor público não é mais fornecido apenas pelo governo, mas sim por colaboração (ANGELIS, 2015, p. 27).
\end{abstract}

Uma das grandes questões que se coloca modernamente é como conseguir, de maneira eficaz, que a participação popular nas mídias digitais se transforme em compromisso do setor público e dos membros dos três poderes na implementação das propostas feitas pela coletividade. Outro desafio é estabelecer métodos eficazes de mensuração desta pressão popular de maneira que a vontade da maioria prevaleça.

Quando envolve os cidadãos, o governo busca obter apoio e legitimidade para suas ações, além de reunir informações que não possui criando instrumentos que permitam ao cidadão participar de diferentes formas, manifestando suas vontades e desejos.

O controle da sociedade sobre as ações governamentais e as políticas públicas no Brasil caminham a passos lentos. É preciso criar uma cultura de participação popular nas decisões do governo e esta cultura está ausente da prática cidadã brasileira: poucos a possuem. $\mathrm{O}$ brasileiro protesta e reclama muito a nível individual (nas filas de bancos, nas filas de caixas de pagamento), mas ainda são poucos os que se mobilizam para pressionar o governo. O novo serviço público, neste cenário, deve promover um sentimento de pertença à comunidade e um vínculo moral com a mesma, indo além da ação racional e pragmática ou burocrática. Nas mídias sociais, é relevante o número de sujeitos que têm a sua frente janelas de oportunidade para se posicionar, cobrar serviços públicos e eficácia governamental. Em nossas pesquisas iniciais, percebemos que os interagentes atuam de forma efetiva no que tange a ações mais imediatas, temporais e R. Inter. Interdisc. INTERthesis, Florianópolis, v.14, n.3, p.16-31 Set.-Dez. 2017 
superficiais: buracos nas ruas, obras em geral, mal funcionamento de serviços, atrações turísticas. Observa-se ainda que este tipo de demanda de caráter prático é mais facilmente atendida pelo gestor público, inclusive pela possibilidade de ser transferida para as mãos dos servidores que estão na ponta do processo, ou seja, os executores. Estas constatações iniciais são reforçadas pelos resultados apresentados por Farranha et alii (2014) e Ellery e Vidal (s.d.) ao analisarem as informações publicadas nas mídias sociais administradas pelo Ministério do Desenvolvimento Agrário/MDA, pela Secretaria Especial de Promoção da Igualdade Racial/SEPPIR e pela Secretaria Especial da Mulher/SPM e pelo Tribunal de Contas do Estado do Ceará.

O setor público está se transformando devido às crescentes demandas sociais e à busca por legitimidade política, o que está alinhado ao novo perfil de brasileiro que habita as mídias sociais: com múltiplas e fluidas identidades, com forte sentimento de territorialidade e em processo de engajamento político. Uma gestão democrática e participativa é o que desejam esses novos movimentos sociais que surgem nas mídias sociais e promovem o ativismo brasileiro do século XXI. O ativismo da atualidade está fortemente ligado às mídias sociais na medida em que os movimentos sociais, com permanência temporal e fortalecido por redes de militância, utilizam-se habilmente do ambiente digital para organizar manifestações políticas a partir da mobilização e organização dos membros de uma comunidade virtual que buscam desencadear reações cidadãs ou reações políticas. O fenômeno do "enxameamento civil"4 (SCHERER-WARREN, 2014) é de fundamental importância para a agregação destas pessoas em torno de signos e símbolos que representam conteúdo político em comum. Os processos mobilizatórios, para esta autora, têm a identidade como essência organizadora, o desejo de transformar valores culturais, o descrédito exponencial nas instituições do Estado e a adoção das TICs ${ }^{5}$ para "convocar, articular, organizar, registrar e partilhar informações sobre as causas" (SCHERER-WARREN, 2014, p. 23).

Scherer-Warren acredita que os movimentos sociais organizados e o ativismo geram mudanças sistêmicas, sociopolíticas e culturais, além de promover novas demandas no campo dos direitos humanos e políticas de fortalecimento da

${ }^{4}$ Aglomerações formadas a partir de uma convocação que não tem uma origem centralizada ou única.

${ }^{5}$ Tecnologias da Informação e Comunicação.

R. Inter. Interdisc. INTERthesis, Florianópolis, v.14, n.3, p.16-31 Set.-Dez. 2017 
cidadania. Desta forma, as políticas institucionais e governamentais, tradicionalmente veiculadas pela mídia de massa, são paulatinamente substituídas pelas "tendências movimentalistas emancipatórias" (SCHERER-WARREN, 2014, p. 23).

Embora submetida a regras criadas e difundidas pelos segmentos socialmente hegemônicos, a Internet, especialmente as mídias sociais, permite que o cidadão com acesso às redes participe na transformação do cenário político no qual está inserido a partir do seu engajamento. $O$ ativismo e muitos processos mobilizatórios como reflexo da formação de grupos digitais são ferramentas que podem fomentar o fortalecimento da cidadania.

\section{CONSIDERAÇÕES FINAIS}

Identidade, território e políticas públicas são conceitos desconectados quando tomados de forma isolada. Contudo, estão absolutamente interligados quando inseridos no ambiente digital, especificamente nas mídias sociais, as quais promovem laços sociais entre seus membros e formação de grupos coletivos a partir de interesses em comum.

A identidade é facilmente associada à liquidez das mídias sociais, as quais permitem que um sujeito isolado possa identificar-se com outros e construir comunidades que aglutinam interesses comuns e agir de maneira organizada, buscando satisfazê-los. Estas comunidades nas quais este sujeito se insere podem, no entanto, defender interesses contraditórios, sem que isto seja compreendido pelo sujeito em questão, caracterizando uma nova forma de alienação.

Este ambiente, por sua vez, torna-se território quando gera em seus membros sentimento de pertencimento e estimula relações sociais e culturais. Quando exercido como contra-espaço, contribui para o ativismo e formação de movimentos sociais organizados, que elaboram estratégias que buscam pressionar os governos de maneira a desenvolver e implementar políticas e ações públicas que favoreçam a democratização da sociedade. 


\title{
IDENTITY, BELONGING AND POLITICAL ENGAGEMENT IN SOCIAL MEDIA
}

\begin{abstract}
:
By adopting an interdisciplinary perspective, this article analyzes the changes introduced by social media in society starting from concepts such as identity, territory and public policies and its transposition to the virtual world, which is considered a multidisciplinary object. Social medias as a territory of belonging, in which is possible for governments to establish mechanisms to control public policies that are more democratic and participative due to virtual interaction, is a premise defended in this article. The end of the article shows how government and community today have the possibility to dialogue and build actions, projects and programs from the engagement and political activism practiced in social networks. As methodology, a bibliographic review was delivered and allowed the discussion of concepts from different areas of knowledge, establishing a relationship between identity, territory and social media.

Keywords: Identity. Territory. Social Media. Multidisciplinarity.
\end{abstract}

\section{IDENTIDAD, PERTENENCIA Y COMPROMISO POLÍTICO EN LOS MEDIOS SOCIALES}

\section{Resumen:}

Adoptando una perspectiva interdisciplinaria, este artículo analiza los cambios introducidos por los medios de comunicación social en la sociedad, partiendo de conceptos como identidad, territorio y políticas públicas y su transposición al mundo virtual, aquí considerado como objeto multidisciplinario. Los medios de comunicación social como territorio de pertenencia, donde es posible a los gobiernos establecer mecanismos de control de políticas públicas más democráticas y participativas, debido a la interacción virtual, son premisas defendidas en este artículo, que al final muestra cómo el gobierno y la comunidad hoy tienen la posibilidad de dialogar y construir acciones, proyectos y programas a partir del compromiso y del activismo político practicado en las redes sociales. Como metodología, se realizó una revisión bibliográfica que permitió la discusión de conceptos oriundos de distintas áreas de conocimiento, estableciendo una relación entre identidad, territorio y medios sociales.

Palabras clave: Identidad. Territorio. Redes sociales. Multidisciplinariedad. 


\section{REFERÊNCIAS}

ANGELIS, C.T. A emergência da reforma do Estado brasileiro: a governança compartilhada e o modelo do novo serviço público. In: Planejamento e políticas públicas, $\mathrm{n} 45$, jul/dez 2015. Disponível em:

$<$ www.ipea.gov.br/ppp/index.php/PPP/article/view/583 > Acesso em 22 abr. 2016.

BAUMAN, Z. Globalização: as consequências humanas. Rio de Janeiro: Jorge Zahar, 1999.

2005.

Identidade: entrevista a Benedetto Vecchi. Rio de Janeiro: Jorge Zahar,

. Modernidade Líquida Rio de Janeiro: Jorge Zahar Editor, 2000.

CARDOSO DE OLIVEIRA, R. Os (descaminhos) da identidade. Revista Brasileira de Ciências Sociais. Vol. 15, $n^{\circ}$ 42, 2000, p. 7-21.

CASTELLS, M. Paraísos comunais: identidade e significado na sociedade em rede. In: CASTELLS, M. $O$ poder da identidade. São Paulo: Paz e Terra, 2001, p. 21-92. Redes de indignação e esperança: movimentos sociais na era da internet. Rio de Janeiro: Zahar, 2013.

ELLERY, A. P. C. e VIDAL, E. M. Ambientes de aprendizagem utilizando mídias sociais na Web como ferramenta de controle social e de apoio à gestão pública: um caminho para o e-government 2.0. CAUED. TCE; UEC: Fortaleza, s.d. Disponível em:<http://reposital.cuaed.unam.mx:8080/jspui/bitstream/123456789/2939/1/Ellery\% 20Corr\%C3\%AAa\%2C\%20Ana.pdf >. Acesso em: 29 jun. 2017.

FARRANHA, A. C. ET ALII. Administração pública e redes sociais (Facebook e Twiter): análise de casos selecionados. Anais do VII Congresso CONSAD de Gestão Pública. Brasília, março 2014. Disponível em:

http://www.escoladegestao.pr.gov.br/arquivos/File/2014/VII Consad/016.pdf Acesso em 29 jun.2017.

HAESBAERT, R. Concepção de território para entender a desterritorialização. In: SANTOS, M. Território, territórios: ensaios sobre o ordenamento territorial. Rio de Janeiro: Lamparina, 2007, p. 43-71.

HALL, S. A identidade cultural na pós-modernidade. 11 ed. Rio de Janeiro: DP\&A, 2006. 
Quem precisa da identidade? In: SILVA, T.T. Identidade e diferença.

Petrópolis: Vozes, 2014. p. 103-133.

HARVEY, D. Condição pós-moderna. 25ª ed. São Paulo: Loyola, 2014.

LEMOS, A. A comunicação das coisas: teoria ator-rede e cibercultura. São Paulo: Annablume, 2013. 310p.

LEMOS, A; LEY,P. O futuro da interne: em direção a uma ciberdemocracia planetária. São Paulo: Paulus, 2010.

MARZULO, E.P. Espaços dos pobres. Identidade social e territorialidade na modernidade tardia. In: ARAUJO; HAESBAERT (Orgs.). Identidades e territórios: questões e olhares contemporâneos. Rio de Janeiro: Access, 2007, p. 57-68.

MOREIRA, R. O espaço e o contra-espaço: as dimensões territoriais da sociedade civil e do Estado, do privado e do público na ordem espacial burguesa. SANTOS, M. Território, territórios: ensaios sobre o ordenamento territorial. Rio de Janeiro: Lamparina, 2007, p. 72-108.

PRIMO, A. Enfoques e desfoques no estudo da interação mediada por computador. In: Intercom 2003-XXVI Congresso Brasileiro de Ciências da Comunicação, 2003, BH, Anais. Acesso em 1 de jul. 2016.

RECUERO, R. Mídia x Rede social. Social Media. Disponível em: http://www.raquelrecuero.com/arquivos/midia $x$ rede social.html Acesso em: 27 de maio de 2016.

Redes sociais na internet. Porto Alegre: Sulina, 2011.

RUEDIGER, M. A. Governo eletrônico e democracia: uma análise preliminar dos impactos e potencialidades na gestão pública. Organizações \& Sociedade, v.9, n.25, p. 29-43, 2002. Disponível em: http://www.scielo.br/pdf/osoc/v9n25/04.pdf Acesso em: 17 mar 2017.

SANTOS, M. O dinheiro e o território. In: SANTOS, M. Território, territórios: ensaios sobre o ordenamento territorial. Rio de Janeiro: Lamparina, 2007, p. 1121. 
SCHERER-WARREN, I. Dos movimentos sociais às manifestações de rua: o ativismo brasileiro no século XXI. Política e Sociedade, Florianópolis, volume $13, n^{\circ}$ 26, set-dez, 2014. p. 13-34.

SILVA, T. T. A produção social da identidade e da diferença. In: SILVA, T. T. Identidade e diferença. Petrópolis: Vozes, 2014. p. 73-102.

SOUZA, C. Políticas públicas: uma revisão da literatura. Sociologias, Porto Alegre, ano 8, n 16, jul/dez 2006, p. 20-45. Disponível em:

www.scielo.br/pdf/soc/n16/a03n16 Acesso em: 26 jul.2016.

WOODWARD, K. Identidade e diferença: uma introdução teórica e conceitual. In: SILVA, T.T. Identidade e diferença. Petrópolis: Vozes, 2014. p. 7-72.

\section{Artigo:}

Recebido em 22 de Outubro de 2016.

Aceito em 04 de Julho de 2017. 